\title{
Serum chromogranin A for the diagnosis of gastroenteropancreatic neuroendocrine neoplasms and its association with tumour expression
}

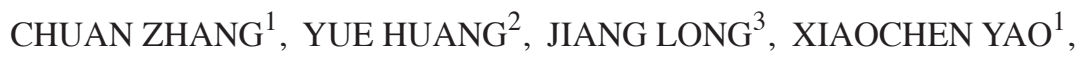 \\ $\mathrm{JUN}_{\text {WANG }}{ }^{1}$, SHIMIN ZANG ${ }^{1}$, WEI QU $^{1}$ and FENG WANG ${ }^{1}$ \\ Departments of ${ }^{1}$ Nuclear Medicine and ${ }^{2}$ Pathology, Nanjing First Hospital, Nanjing Medical University, Nanjing, \\ Jiangsu 210006; ${ }^{3}$ Department of Pancreas Surgery, Fudan University Shanghai Cancer Centre, Shanghai 200032, P.R. China
}

Received February 25, 2018; Accepted October 3, 2018

DOI: $10.3892 / \mathrm{ol} .2018 .9795$

\begin{abstract}
The aim of the present study was to assess the clinical value of serum chromogranin $\mathrm{A}(\mathrm{CgA})$ levels in patients with gastroenteropancreatic neuroendocrine neoplasms (GEP-NENs) and to compare them with tumour expression of CgA. A total of 109 consecutive patients with confirmed GEP-NENs were enrolled in this prospective study between December 2012 and August 2016, including 73 patients with primary or recurrent GEP-NENs and 36 patients with GEP-NENs that were treated following surgery. Furthermore, 30 patients with benign gastrointestinal diseases and 30 healthy volunteers served as control groups. Serum CgA levels were measured by ELISA, using different reference values, in order to evaluate its diagnostic efficacy. Serum neuron-specific enolase was also measured to evaluate its diagnostic efficacy and analyse its association with serum $\mathrm{CgA}$ levels. The levels of $\mathrm{CgA}$, synaptophysin and neural cell adhesion molecule 1 in the tumour tissue were assessed by immunohistochemical assays. The results indicated that serum $\mathrm{CgA}$ levels were significantly higher in patients with GEP-NENs compared with the control groups $(\mathrm{P}<0.05)$. No association was observed between serum CgA levels and tumour grade (G1, G2 and G3), but serum $\mathrm{CgA}$ levels differed significantly between patients
\end{abstract}

Correspondence to: Dr Wei Qu or Dr Feng Wang, Department of Nuclear Medicine, Nanjing First Hospital, Nanjing Medical University, 68 Changle Road, Nanjing, Jiangsu 210006, P.R. China E-mail: njquwei@163.com

E-mail: fengwangcn@hotmail.com

Abbreviations: $\mathrm{CgA}$, chromogranin A; GEP-NEN, gastroenteropancreatic neuroendocrine neoplasm; NEN, neuroendocrine neoplasm; NSE, neuron-specific enolase; IHC, immunohistochemistry; ROC, receiver operating characteristic; AUC, area under the curve

Key words: chromogranin A, neuroendocrine neoplasm, gastroenteropancreatic endocrine tumour, tumour grade, tumour origin, reference value, neuron-specific enolase with GEP-NENs of different origins $(\mathrm{P}<0.05)$. A serum $\mathrm{CgA}$ cut-off value of $85.3 \mathrm{ng} / \mathrm{ml}$ was associated with high sensitivity $(64.4 \%)$ and specificity $(92.7 \%)$. Different reference values were recommended for NENs of different origins, with serum CgA cut-off values of 96.72, 51.13 and $86.19 \mathrm{ng} / \mathrm{ml}$ for the stomach, intestines and pancreas, respectively. The serum $\mathrm{CgA}$ levels were consistent with the $\mathrm{CgA}$ expression in the tumour. In conclusion, serum $\mathrm{CgA}$ may serve as a circulating pathological biomarker for the diagnosis of GEP-NENs. The use of different reference values for different tumour origins may improve the diagnostic efficacy of $\mathrm{CgA}$ for GEP-NENs. A cut-off value of $85.3 \mathrm{ng} / \mathrm{ml}$ is recommended in the Chinese population.

\section{Introduction}

Chromogranin A (CgA), a member of the chromogranin family, is an acidic and hydrophilic glycoprotein (1). It is widely distributed in various tissues, including the sympathetic nerve endings, cardiac muscle, pancreas, the central and peripheral nervous system, intestinal endocrine tissues, and the thyroid and parathyroid glands, and can be degraded into a series of smaller, biologically active peptides. CgA has been recognised as the most important tumour marker in functioning and non-functioning neuroendocrine neoplasms (NENs), and is valuable for evaluating postoperative recurrence and prognosis (2). Neuron-specific enolase (NSE) is a glycolytic enzyme that is present in the cytoplasm of neurons and neuroendocrine cells (3). This enzyme is expressed in various tumour types with neuroendocrine differentiation, including small-cell lung cancer and poorly differentiated NENs, for differentiating NENs from non-endocrine tumours (4).

NENs arising from the diffuse endocrine system can occur in any organ of the body. The most common sites are the ileum and pancreas, with NENs in the thymus, breast, stomach, colon, ovary and cervix being less common. Notably, serum CgA levels vary according to the origin of the tumour. The incidence of NENs in China has increased in the last decade (5), with a study showing the most common primary sites of gastroenteropancreatic (GEP) NENs to be the pancreas $(31.5 \%)$ and rectum $(29.6 \%)$, followed by the 
cardia (11.6\%) and body (15.4\%) of the stomach, with small intestinal and colonic NENs occurring in a small proportion of all patients. Compared with cardiac and gastric body NENs, pancreatic and rectal NENs tended to be found in younger, female, urban residents with a higher education level, who were diagnosed at an earlier stage and lower grade (6). The therapy of GEP-NENs, including biotherapy, systemic chemotherapy and somatostatin receptor radionuclide therapy, have made significant progress, but surgical therapy still occupies an important position (7). It has been reported that $\sim 60 \%$ of patients will have recurrence following radical surgery, and the 5-year survival rate of local and regional metastases was $35-80 \%$ (8). A large scale study including 35,097 cases indicated that the median survival duration in G1 and G2 NENs was 124 and 64 months, respectively, whereas that of poorly differentiated NENs was only 10 months (6). However, serum $\mathrm{CgA}$ assays are not widely used in China, and serum $\mathrm{CgA}$ measurements for the diagnosis of NENs, particularly in different primary tumour sites, have been validated in a small number of clinical centres or laboratories. The aim of the present study was to investigate the clinical role of serum $\mathrm{CgA}$ levels in patients with GEP-NENs of different primary tumour origins and different stages, and to determine the optimal cut-off values for specific primary tumour sites, with the aim of increasing the sensitivity of serum $\mathrm{CgA}$ for the diagnosis of GEP-NENs.

\section{Materials and methods}

Patients and clinical characteristics. Among the 109 patients with GEP-NENs, 59 were females and 50 were males (mean age, 54 years; range, 21-79 years). They were monitored at the Nanjing First Hospital (Nanjing, China) between December 2012 and August 2016. The diagnosis was confirmed in all patients by histopathology and imaging follow-up (computerized tomography or magnetic resonance imaging). All 109 patients with GEP-NENs received a serum $\mathrm{CgA}$ test. The patients were divided into 2 groups: Group 1 included 73 patients with detectable lesions (38 patients with primary lesions prior to resection and 35 with recurrence and metastasis following primary tumor resection); and Group 2 included 36 patients with no detectable lesions post-surgery, as confirmed by anatomical and functional imaging follow-up. Serum CgA levels in 73 patients with detectable lesions were further analysed according to clinical characteristics. Among the 109 patients with GEP-NENs, $52(47.1 \%)$ were confirmed with pancreatic, $22(20.2 \%)$ with gastric and 35 (32.1\%) with intestinal neuroendocrine tumours. According to WHO 2010 international consensus diagnostic criteria (9), 29 patients $(26.6 \%)$ had G1 tumours, 55 (50.5\%) had G2 tumours and 25 (22.9\%) had G3 tumours. The control groups included 30 healthy volunteers (Group 3) and 30 patients with other digestive tract diseases, including a number of types of gastritis, with atrophic gastritis included, and non-neuroendocrine gastric cancer (Group 4). Among the 109 patients, only 59 patients volunteered to receive the NSE test. These patients were also divided into 2 groups: Group 5 included 18 patients with no detectable lesions post-surgery and Group 6 included 41 patients with detectable lesions (primary lesions prior to resection and

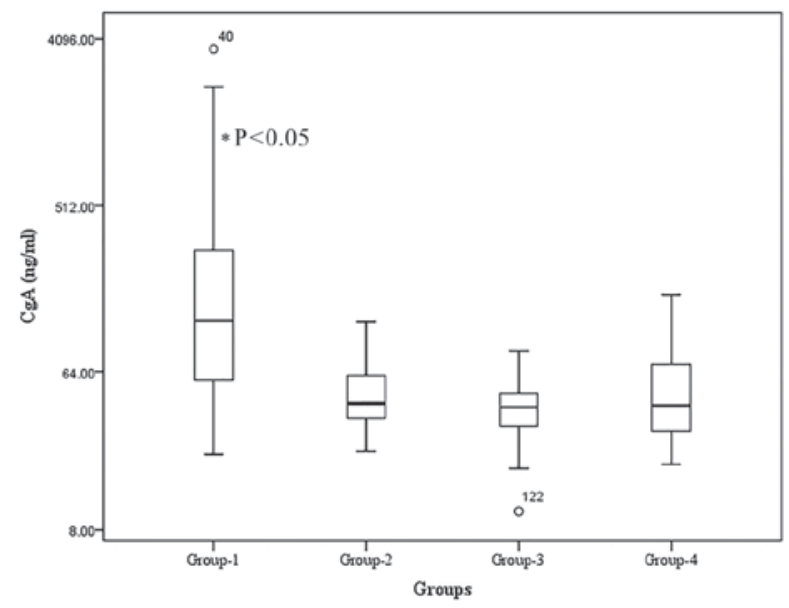

Figure 1. Serum CgA levels in 73 patients with naive or recurrent GEP-NENs (Group 1), 36 patients with GEP-NEN cured following surgery (Group 2), 30 healthy controls (Group 3) and 30 patients with other digestive tract diseases (Group 4). There was a statistically significant difference between Group 1 and the other three groups (Groups 2-4). "P<0.05 compared with other groups. $\mathrm{CgA}$, chromogranin A; GEP-NEN, gastroenteropancreatic neuroendocrine neoplasm.

recurrence and metastasis following primary tumor resection). Serum NSE levels in 41 patients with detectable lesions were also analysed according to clinical characteristics. A total of 30 healthy volunteers received a NSE test as a control group (Group 7). There were no significant sex or age differences between the control groups. All patients gave written informed consent to participate in the study at the Nanjing Medical University (Nanjing, China).

Measurement of serum $\mathrm{CgA}$ and NSE. Serum samples were collected following overnight fasting, stored at $-20^{\circ} \mathrm{C}$ until use, and thawed immediately prior to each assay. Serum $\mathrm{CgA}$ was measured by sandwich ELISA using a commercial Chromoa assay kit (Cisbio, Codolet, France), which uses 2 monoclonal antibodies directed against the $\mathrm{CgA}$ amino acids at locations 145-197 and 198-245. A first monoclonal antibody, immobilized on the microplate, captures the $\mathrm{Cg} A$ proteins contained in the calibrators and samples. A second monoclonal antibody is added, forming a complex with the antigen. Finally, the microplate is developed by adding an enzymatic substrate to produce a visible signal, which indicates the quantity of antigen in the sample. The NSE values were measured in serum samples using the Roche chemiluminescence analyser (Roche Diagnostics GmbH Mannheim, Germany).

Histopathology. The CgA, synaptophysin (Syn) and neural cell adhesion molecule 1 (CD56) are hallmarks of NENs in pathology $(9,10)$. The diagnosis was confirmed in all patients by histopathology, but only a subset of pathology samples of patients were collected for immunohistochemistry (IHC). The $\mathrm{CgA}$, Syn and CD56 expression in the tumour samples of the patients with naïve or recurrent GEP-NENs were detected by IHC. Paraffin-embedded tissue sections $(4 \mu \mathrm{m})$ were fixed with $10 \%$ formalin for $24 \mathrm{~h}$ at room temperature, deparaffinized in xylene and rehydrated in graded anhydrous alcohol solutions (90, 80 and 70\%). Sections were blocked for $30 \mathrm{~min}$ 

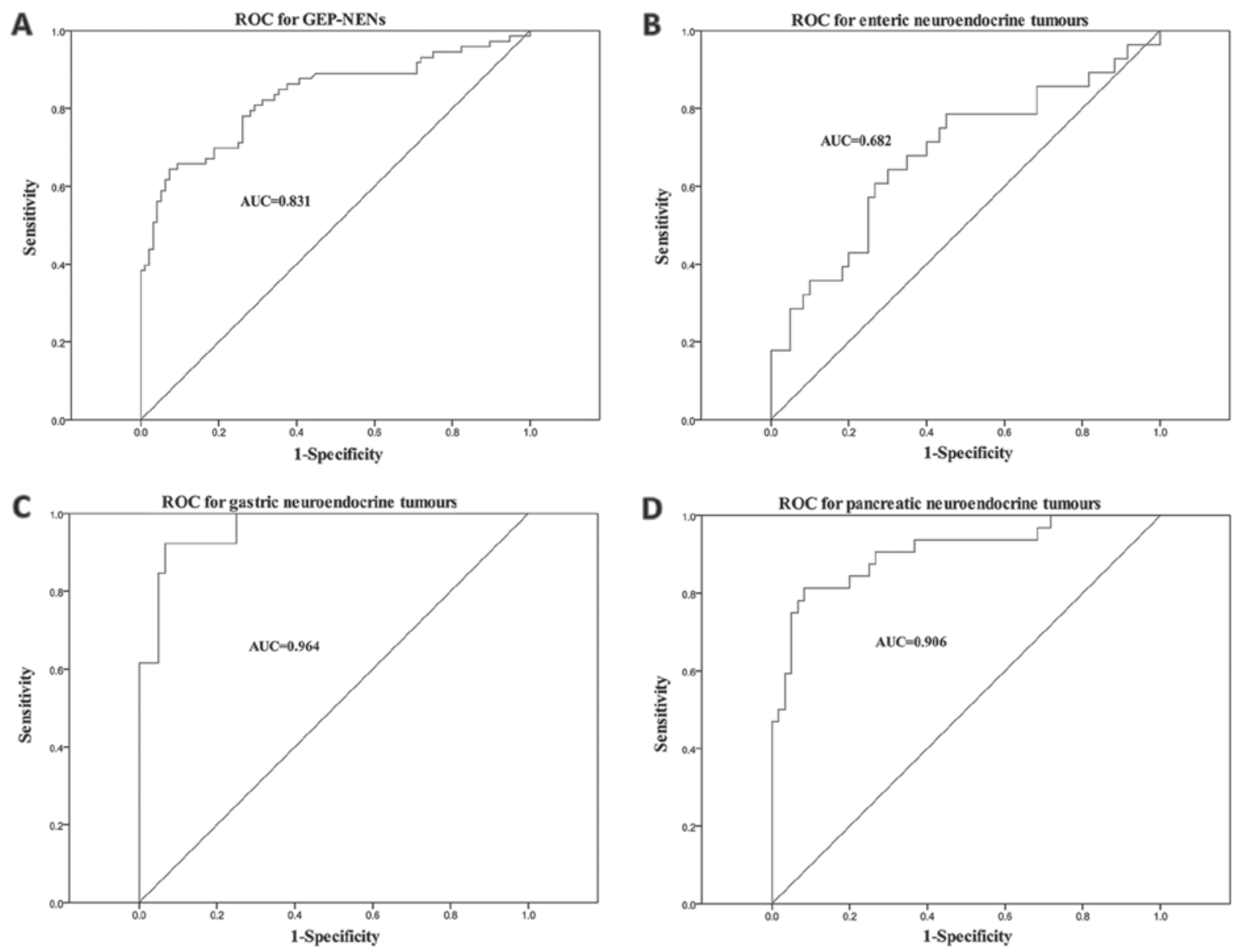

Figure 2. ROC curve analyses of chromogranin A levels in the serum of patients with GEP-NENs and the control group. ROC curves for (A) 73 patients with GEP-NENs, (B) 28 patients with enteric NENs, (C) 13 patients with gastric NENs and (D) 32 patients with pancreatic NENs. ROC, receiver operating characteristic; AUC, area under the curve; GEP-NEN, gastroenteropancreatic neuroendocrine neoplasm.

in $\mathrm{H}_{2} \mathrm{O}_{2}(3 \%)$ at room temperature, and underwent antigen retrieval by boiling $\left(95-99^{\circ} \mathrm{C}\right)$ for $4 \mathrm{~min}$ at max power, and for $12 \mathrm{~min}$ at $50 \%$ power. Subsequently, sections were cooled down for $30 \mathrm{~min}$, rinsed three times with PBS and incubated with normal goat serum (cat. no. X090710-8; Dako; Agilent Technologies, Inc., Santa Clara, CA, USA) for $30 \mathrm{~min}$ at room temperature, followed by overnight incubation at $4^{\circ} \mathrm{C}$ with antibodies against Syn (Ready-to-use; Syn:AM363-5M; snp88; BioGenex, Fremont, CA, USA), CgA (Ready-to-use; CgA:AM126-5M; LK2H10; BioGenex, Fremont, CA, USA) or CD56 (Ready-to-use; CD56:003218; 123C3; Zymed; Thermo Fisher Scientific, Inc., Waltham, MA, USA). Next day, sections were washed three times with PBS and incubated for $30 \mathrm{~min}$ at room temperature with a goat anti-mouse secondary antibody (cat. no. K400111-2; EnVisionTM+/HRP,Mo, $110 \mathrm{ml}$, Ready-to-use, Dako). Subsequently, washed with PBS, then the substrate chromogen, DAB, enabled visualization of the complex via a brown precipitate. Sections were counterstained with hematoxylin for $1 \mathrm{~min}$ at room temperature and were mounted using coverslips. Tissues were analysed with a light microscope (BX51; Olympus Corporation, Tokyo, Japan; magnification, x100-400). All biopsy samples were interpreted by 3 certified pathology physicians(Nanjing First Hospital, China) who were blinded to the patients' clinical data according to the classification criteria of the pathological diagnosis of gastrointestinal neuroendocrine tumours (WHO, 2010) (9) and the Chinese Consensus Guidelines (10).

Statistical analysis. All data were presented as median values with interquartile ranges. The serum CgA and NSE levels were compared between subgroups using the Mann-Whitney or Kruskal-Wallis tests, and Dunn-Bonferroni post hoc test. The diagnostic value of the serum CgA levels in GEP-NENs was investigated by calculating the area under the curve (AUC) for each receiver operating characteristic (ROC) curve. The CgA cut-off values that produced the highest sensitivity and specificity were determined. The correlation between serum NSE levels and serum CgA levels was evaluated by the Pearson's correlation test. The correlation between tumour $\mathrm{CgA}$ expression and serum $\mathrm{CgA}$ levels was analysed by the Spearman's correlation method. All statistical analyses were carried out using SPSS statistical software version 19.0 (IBM Corp., Armonk, NY, USA). P<0.05 was considered to indicate statistically significant differences.

\section{Results}

Serum CgA in GEP-NENs. The median serum CgA level in Group 1 was 121.16 ng/ml, which was significantly higher compared with that in Groups 2, 3 and 4 (42.77, 40.51 and 
Table I. Serum CgA levels in patients with primary or advanced gastroenteropancreatic neuroendocrine neoplasms ( $\mathrm{n}=73$ ) using Kruskal-Wallis test.

\begin{tabular}{|c|c|c|c|c|}
\hline Variables & $\mathrm{n}$ & Median CgA level, ng/ml (range) & Z-value & P-value \\
\hline Age, years & & & 0.998 & 0.319 \\
\hline$<54$ & 33 & $155.64(56.77-421.01)$ & & \\
\hline$\geq 54$ & 40 & $110.23(57.46-213.29)$ & & \\
\hline Sex & & & 0.000 & 1.000 \\
\hline Male & 40 & $110.23(58.18-300.28)$ & & \\
\hline Female & 33 & $143.69(56.77-326.93)$ & & \\
\hline Tumour site & & & 19.681 & $<0.001$ \\
\hline Stomach & 13 & $259.95(112.73-1442.34)$ & & \\
\hline Intestines & 28 & $57.665(44.12-109.41)$ & & \\
\hline Pancreas & 32 & $161.95(102.24-367.14)$ & & \\
\hline Grade & & & 3.359 & 0.186 \\
\hline G1 & 17 & $105.09(56.96-272.44)$ & & \\
\hline $\mathrm{G} 2$ & 40 & $123(49.17-287.94)$ & & \\
\hline G3 & 16 & $178.5(104.97-578.22)$ & & \\
\hline Lesions & & & 2.260 & 0.024 \\
\hline Primary & 38 & $146.71(66.33-419.7)$ & & \\
\hline Recurrent & 35 & $103.24(45.5-186.43)$ & & \\
\hline Metastasis & & & 0.743 & 0.458 \\
\hline No & 14 & $125.93(66.33-419.7)$ & & \\
\hline Yes & 59 & $115.31(53.59-293.96)$ & & \\
\hline $\mathrm{IHC}(\mathrm{CgA})$ & & & 2.277 & 0.023 \\
\hline - & 13 & $56.66(34.04-94.78)$ & & \\
\hline+ & 47 & $155.64(58.08-405.56)$ & & \\
\hline IHC (CD56) & & & 0.398 & 0.690 \\
\hline- & 5 & $108.35(67.23-223.77)$ & & \\
\hline+ & 36 & $112.81(56.29-415.18)$ & & \\
\hline IHC (Syn) & & & 0.531 & 0.596 \\
\hline- & 1 & $-{ }^{\mathrm{a}}$ & & \\
\hline+ & 61 & $115.31(54.84-350.37)$ & & \\
\hline
\end{tabular}

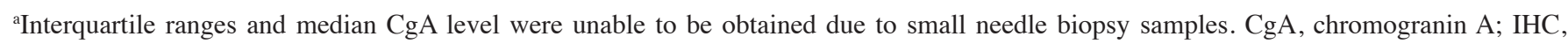
immunohistochemistry; CD56, neural cell adhesion molecule 1; Syn, synaptophysin.

$41.41 \mathrm{ng} / \mathrm{ml}$, respectively; $\mathrm{P}<0.05$ ) (Fig. 1). No significant differences were observed among the serum $\mathrm{CgA}$ levels of Groups 2, 3 and 4. Values 40 and 122 indicated in the figure represent the outliers at the 40 th and 122 nd positions.

Cut-off levels for serum CgA and diagnostic efficacy. The serum CgA levels in GEP-NEN samples were measured and a ROC curve was plotted (Fig. 2A). A total of 109 patients with GEP-NENs participated, including 73 patients with primary or detectable lesions (positive controls), 36 patients with a history of GEP-NENs, who had been treated surgically, 30 patients with other digestive tract diseases and 30 healthy volunteers (negative controls). The ROC curve for the serum CgA levels revealed that a cut-off value of $85.3 \mathrm{ng} / \mathrm{ml}$ led to $64.4 \%$ sensitivity and $92.7 \%$ specificity (AUC, 0.831 ) for the diagnosis of GEP-NENs.
The ROC curves of serum CgA levels of the 73 patients with detectable lesions grouped according to different tumour origins are presented in Fig. 2B-D. Overall, 32 primary lesions originated from the pancreas, 13 from the stomach and 28 from the intestines. The optimal serum $\mathrm{CgA}$ concentration cut-off values were $86.19 \mathrm{ng} / \mathrm{ml}$ for pancreatic NENs (sensitivity, $81.3 \%$; specificity, 91.7\%), $96.72 \mathrm{ng} / \mathrm{ml}$ for gastric NENs (sensitivity, 92.3\%; specificity, 93.3\%) and $51.13 \mathrm{ng} / \mathrm{ml}$ for intestinal NENs (sensitivity, 64.3\%; specificity, 70.0\%). Serum CgA levels were significantly increased in patients with gastric NENs even at an early stage, whereas rectal NENs had low levels of serum CgA

Serum CgA levels in patients with GEP-NENs according to various clinical features. Serum $\mathrm{CgA}$ levels and patient characteristics are listed in Table I. The median serum CgA level in patients with gastric NENs was higher compared with that in 


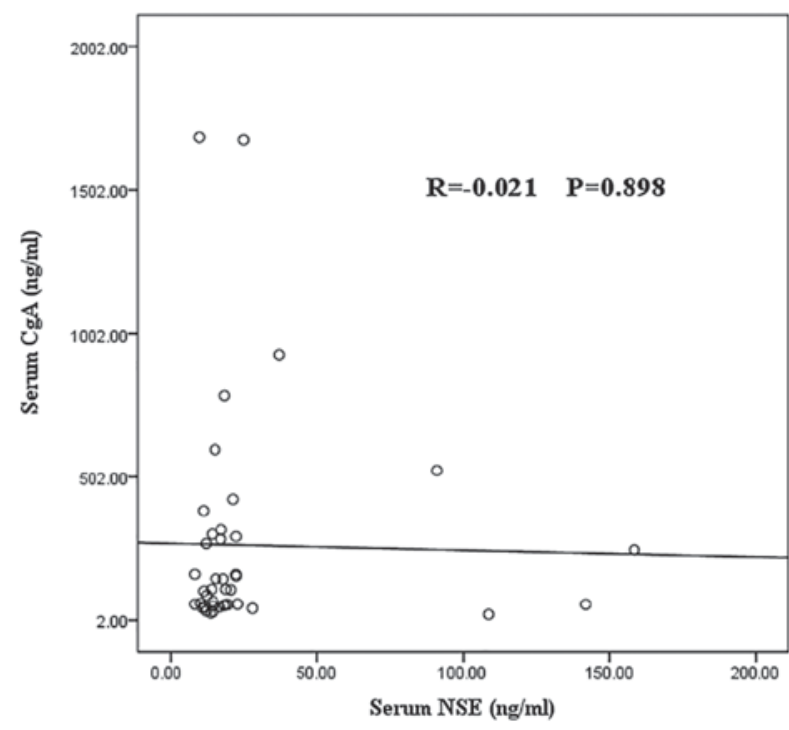

Figure 3. Pearson's correlation analysis of serum NSE and CgA levels in patients with gastroenteropancreatic neuroendocrine neoplasms. $\mathrm{CgA}$, chromogranin A; NSE, neuron-specific enolase.

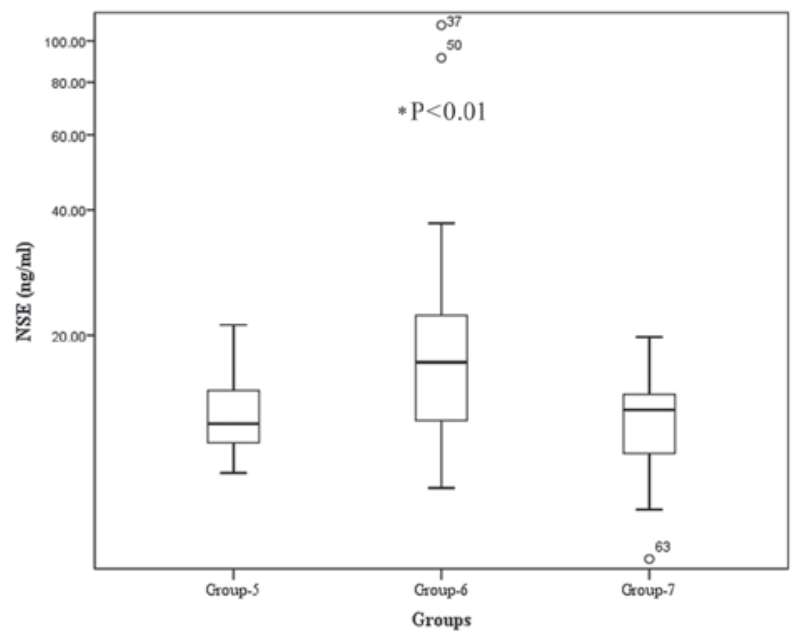

Figure 4. Serum NSE levels in patients with gastroenteropancreatic neuroendocrine neoplasms and controls. Group 5, patients with no detectable lesions post-resection $(\mathrm{n}=18)$; Group 6, patients with naive or recurrent GEP-NENs $(\mathrm{n}=41)$; Group 7 , healthy controls $(\mathrm{n}=30)$. There was a statistically significant difference between Group 6 and other two groups (Groups 5 and 7). ${ }^{*} \mathrm{P}<0.01$ compared with other groups. NSE, neuron-specific enolase.

patients with pancreatic or intestinal NENs (259.95, 161.95 and $57.67 \mathrm{ng} / \mathrm{ml}$, respectively; $\mathrm{P}<0.05)$. The median serum level of $\mathrm{CgA}$ in patients with post-surgical recurrence or metastasis was significantly lower compared with that in patients with untreated primary lesions (103.24 and $146.71 \mathrm{ng} / \mathrm{ml}$, respectively; $\mathrm{P}<0.05$ ), and the median serum level in patients with IHC-positive $\mathrm{CgA}$ expression in their biopsy samples was significantly higher compared with that in patients without tumour $\mathrm{CgA}$ expression $(\mathrm{P}<0.05)$. Serum $\mathrm{CgA}$ levels in patients with GEP-NENs was not associated with sex, age, grade, metastasis or CD56 expression.

Correlation between serum and tumour CgA expression levels. The data were divided into positive and negative

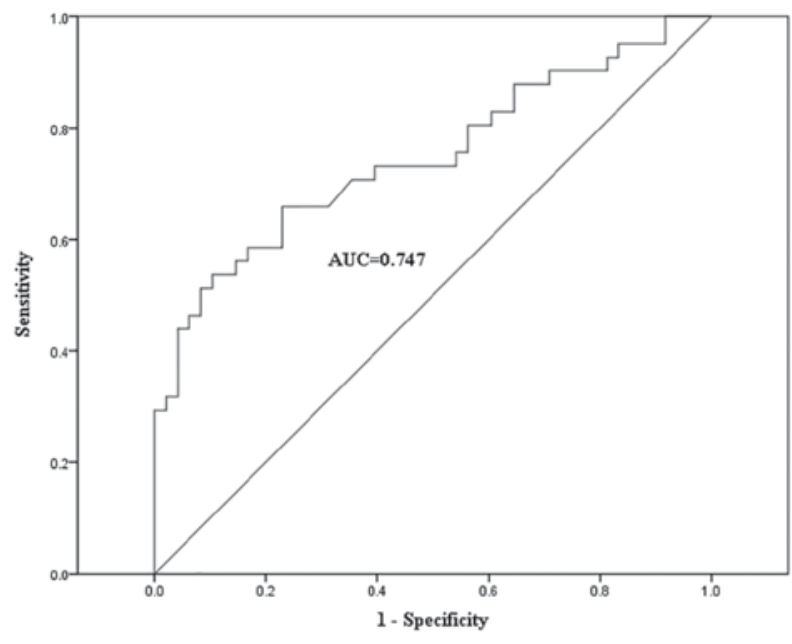

Figure 5. Receiver operating characteristic curve of serum NSE concentrations in the control group and patients with gastroenteropancreatic neuroendocrine neoplasms. AUC, area under the curve.

groups based the serum CgA cut-off value of $85.3 \mathrm{ng} / \mathrm{ml}$. The serum and tumour $\mathrm{CgA}$ statuses were analysed among the 73 patients with naive or recurrent GEP-NENs, and the results demonstrated that significantly increased serum $\mathrm{CgA}$ levels were consistent with positive $\mathrm{CgA}$ expression in 32 out of 60 patients (53.3\%). The Spearman's correlation analysis revealed a correlation between serum $\mathrm{CgA}$ levels and tumour $\mathrm{CgA}$ expression $(\mathrm{R}=0.41, \mathrm{P}=0.001)$ (data not shown).

Correlation between serum CgA and NSE levels. No correlation was observed between the serum $\mathrm{CgA}$ and NSE levels in 41 patients with detectable GEP-NENs $(\mathrm{R}=-0.021 ; \mathrm{P}=0.9)$ (Fig. 3).

Serum NSE levels in patients with GEP-NENs. The serum NSE levels were significantly higher in patients with naive or recurrent GEP-NENs (Group 6), compared with those with no detectable lesions post-surgery (Group 5) or the healthy controls. The median NSE level in patients with naive or recurrent NENs (Group 6) was $17.15 \mathrm{ng} / \mathrm{ml}$, compared with 12.12 and $13.1 \mathrm{ng} / \mathrm{ml}$ in the treated group (Group 5) and control group (Group 7), respectively (P<0.01; Fig. 4). A ROC curve analysis of serum NSE levels was performed in 89 individuals (Fig. 5), including 41 patients with naive or recurrent GEP-NENs, 18 patients with treated GEP-NENs and 30 healthy volunteers (negative controls). The ROC curve indicated that a serum NSE cut-off concentration of $16.48 \mathrm{ng} / \mathrm{ml}$ gives $53.7 \%$ sensitivity and $89.6 \%$ specificity (AUC, 0.747 ). The diagnostic efficacy of serum NSE is demonstrated in Table II. No significant association was observed between the serum NSE levels and any clinical characteristics in patients with GEP-NENs, including sex, age, primary tumour origin, grading, metastasis, surgical status, or $\mathrm{CgA}$ or $\mathrm{CD} 56$ expression.

\section{Discussion}

The worldwide incidence of NENs has risen markedly in recent years, leading to widespread concern (6). The incidence of GEP-NENs in China increased consistently between 2001 and 
Table II. Diagnostic value of serum NSE concentration in patients with gastroenteropancreatic neuroendocrine neoplasms $(\mathrm{n}=41)$.

\begin{tabular}{|c|c|c|c|c|}
\hline Variables & $\mathrm{n}$ & Median NSE level, ng/ml (range) & Z-value & P-value \\
\hline Age, years & & & 0.392 & 0.695 \\
\hline$<54$ & 22 & $17.64(13.74-21.6)$ & & \\
\hline$\geq 54$ & 19 & $14.48(12.1-22.36)$ & & \\
\hline Sex & & & 0.440 & 0.660 \\
\hline Male & 27 & $17.15(12.13-21.34)$ & & \\
\hline Female & 14 & $17.38(13.24-24.13)$ & & \\
\hline Tumour site & & & 1.379 & 0.502 \\
\hline Stomach & 5 & $18.94(10.56-20.45)$ & & \\
\hline Intestines & 16 & $14.48(12.48-20.01)$ & & \\
\hline Pancreas & 20 & $17.87(12.9-22.75)$ & & \\
\hline Grade & & & 0.317 & 0.854 \\
\hline G1 & 7 & $17.15(12.1-21.34)$ & & \\
\hline G2 & 27 & $15.44(12.13-22.38)$ & & \\
\hline G3 & 7 & $18.01(15.16-19.55)$ & & \\
\hline Lesions & & & 0.947 & 0.343 \\
\hline Primary & 15 & $19.55(13.96-22.36)$ & & \\
\hline Recurrent & 26 & 15 (12.12-19.8) & & \\
\hline Metastasis & & & 0.801 & 0.423 \\
\hline No & 3 & $13.96^{\mathrm{a}}$ & & \\
\hline Yes & 38 & $17.21(12.29-22.37)$ & & \\
\hline IHC (CgA) & & & 1.789 & 0.074 \\
\hline- & 8 & $14.05(11.52-17.87)$ & & \\
\hline+ & 29 & $18.47(13.27-22.63)$ & & \\
\hline IHC (CD56) & & & 0.386 & 0.700 \\
\hline- & 3 & $17.27^{\mathrm{a}}$ & & \\
\hline+ & 24 & $16.945(12.11-19.4)$ & & \\
\hline
\end{tabular}

${ }^{a}$ Interquartile ranges were unable to be obtained because of small needle biopsy samples. NSE, neuron-specific enolase; $\mathrm{CgA}$, chromogranin A; IHC, immunohistochemistry; CD56, neural cell adhesion molecule 1.

2010, with the highest increases being in rectal and pancreatic NENs $(5,11)$. Serum CgA is a reliable circulating maker for the diagnosis of NENs and is associated with tumour mass and patient survival $(2,12-15)$. In the present study, it was demonstrated that serum CgA levels were significantly higher in patients with GEP-NENs compared with healthy controls, and that they decreased to baseline concentrations in patients who were treated following surgery. Serum CgA level may therefore serve as a predictor of therapeutic response. GEP-NENs have a wide spectrum of clinical presentations ranging from clinically silent to tumour-derived peptide-associated symptoms, including flushing and diarrhoea. In the present study, the serum $\mathrm{CgA}$ concentrations were significantly higher in patients with GEP-NENs compared with those with other digestive tract diseases $(121.16 \mathrm{ng} / \mathrm{ml} \mathrm{vs} .41 .41 \mathrm{ng} / \mathrm{ml})$, suggesting that this may be a useful tool for differentiating between GEP-NENs and other digestive tract disorders.

Serum CgA was previously demonstrated to be associated with tumour burden, treatment response and prognosis $(2,13,14,16)$. However, in contrast to the results of a previous study (17), the $\mathrm{CgA}$ levels measured in the present study were not significantly associated with age, sex or tumour burden, and no difference was revealed in serum $\mathrm{CgA}$ levels with regards to tumour grade (G1, G2 and G3). This discrepancy may be due to different tumour origins. The variability of serum $\mathrm{CgA}$ levels in patients with GEP-NENs may be explained by the difference in tumour origin, differentiation and stage (18).

The WHO classification system introduced in 2000 was based on a combination of pathological and clinical parameters, and a new classification system focusing on staging and grading systems was provided in 2010 (9). However, NENs of different origins are associated with different biological behaviours, and the G3 category includes a small number of tumours $(>20 \%)$ with well-differentiated characteristics, including cell structure and alignment, and a proliferation marker protein Ki-67 index. To date, few studies have analysed the association between NEN origin and serum CgA $(19,20)$. In the present study, the optimal serum $\mathrm{CgA}$ cut-off values were determined for patients with tumours of different origins, and it was revealed that serum $\mathrm{CgA}$ levels were higher in patients with gastric NENs compared with those with pancreatic or intestinal NENs $(259.95,161.95$ and $57.67 \mathrm{ng} / \mathrm{ml}$, respectively; 
$\mathrm{P}<0.001)$. In addition, serum $\mathrm{Cg} \mathrm{A}$ levels were significantly increased in patients with gastric NENs even at an early stage, whereas rectal NENs had low levels of serum CgA. Serum $\mathrm{Cg} \mathrm{A}$ was therefore revealed to be associated with tumour origin, as well as tumour staging. Future studies will focus on the association between serum $\mathrm{CgA}$ and tumor burden. The results indicate that serum $\mathrm{CgA}$ may assist in identifying the tumour location, and understanding the variability in $\mathrm{CgA}$ levels in GEP-NEN cases reported by various studies $(2,17,19)$.

To the best of our knowledge, only one study investigated the CgA cut-off value for diagnosing GEP-NENs in Chinese populations. In the present study, a cut-off value of $85.3 \mathrm{ng} / \mathrm{ml}$ serum $\mathrm{CgA}$ led to a sensitivity and specificity of 64.4 and $92.7 \%$, respectively (AUC 0.83). This cut-off value is lower compared with the recommended threshold of $95 \mathrm{ng} / \mathrm{ml}$, giving the best compromise between sensitivity (51.2\%) and specificity $(87.5 \%)$, calculated in a previous study (21). The present study was the second to calculate a cut-off value for serum $\mathrm{CgA}$ in a Chinese population. The lower cut-off value of $85.3 \mathrm{ng} / \mathrm{ml}$ was associated with higher sensitivity. Different serum $\mathrm{CgA}$ cut-off values were determined for the detection of tumours at different sites, with a threshold of $96.72 \mathrm{ng} / \mathrm{ml}$ providing high sensitivity $(92.3 \%)$ and specificity $(93.3 \%)$ for gastric NENs. However, a lower cut-off value $(51.13 \mathrm{ng} / \mathrm{ml})$ was recommended for enteric NENs, associated with moderate sensitivity $(64.3 \%)$ and specificity (70\%). Furthermore, it was demonstrated that high serum $\mathrm{CgA}$ levels were significantly correlated with tumour $\mathrm{CgA}$ expression $(\mathrm{R}=0.341, \mathrm{P}=0.015)$. However, IHC CgA expression in enteric NENs has previously been demonstrated to be lower compared with that in gastric NENs (22), which is consistent with the lower serum CgA levels in enteric NENs determined in the present study. Serum CgA demonstrated a lower sensitivity for detecting colon and rectal NENs, whereas secretagogin (SCGN) was more sensitive as a diagnostic marker for rectal NENs $(23,24)$. The diagnostic value of $\mathrm{CgA}$ combined with SCGN for the detection of rectal NENs will be explored in future studies.

NSE is the neuron-specific isomer of the glycolytic enzyme 2-phospho-D-glycerate hydrolase (or enolase), and is highly expressed in NENs. In the present study, serum NSE levels were revealed to be significantly higher in patients with advanced stage or recurrent disease compared with patients who had their condition controlled surgically. Significantly increased serum NSE levels may indicate poor differentiation and a poor prognosis (25-27); however, no significant correlation between serum NSE and $\mathrm{CgA}$ levels was observed in patients with GEP-NENs in the present study.

Serum CgA levels may vary according to the origin of GEP-NENs. An overall cut-off value of $85.3 \mathrm{ng} / \mathrm{ml}$ is recommended for the diagnosis of NENs in the Chinese population, but different cut-off values are recommended for tumours depending on their origin. However, the present study was conducted on a small population size from a single centre, and further large-scale population studies are required to clarify the role of serum $\mathrm{CgA}$ concentrations in patients with GEP-NENs.

\section{Acknowledgements}

Not applicable.

\section{Funding}

The present study was supported by grants from the National Natural Science Foundation of China (grant no. 81271604) and the Jiangsu Provincial Nature Science Foundation (grant nos. BL2012037 and BK2011104).

\section{Availability of data and materials}

The datasets used and analysed during the present study are available from the corresponding author on reasonable request, once the study has been published.

\section{Authors' contributions}

CZ, WQ and FW were in charge of design and implementation of the study. CZ was in charge of statistical analysis and writing the draft. FW made substantial contributions to conception, framework and design. YH was in charge of pathological interpretation. WQ was in charge of laboratory assays and quality control, including NSE and $\mathrm{CgA}$ analysis. JL, XY, JW and SZ made substantial contributions to clinical data collection and clinical management. All authors were involved in drafting, reading and approving the manuscript, and all agree to be accountable for the results.

\section{Ethics approval and consent to participate}

The present study was approved by the Ethics Committee of Nanjing First Hospital, Nanjing Medical University. Written informed consent to participate was obtained from all participants, using a formulary approved by the Ethics Committee.

\section{Patient consent for publication}

Not applicable.

\section{Competing interests}

The authors declare that they have no competing interests.

\section{References}

1. Konecki DS, Benedum UM, Gerdes HH and Huttner WB: The primary structure of human chromogranin A and pancreastatin. J Biol Chem 262: 17026-17030, 1987.

2. Modlin IM, Gustafsson BI, Moss SF, Pavel M, Tsolakis AV and Kidd M: Chromogranin A--biological function and clinical utility in neuro endocrine tumor disease. Ann Surg Oncol 17: 2427-2443, 2010

3. Påhlman S, Esscher T, Bergvall P and Odelstad L: Purification and characterization of human neuron-specific enolase: Radioimmunoassay development. Tumour Biol 5: 127-139, 1984.

4. Baudin E, Gigliotti A, Ducreux M, Ropers J, Comoy E, Sabourin JC, Bidart JM, Cailleux AF, Bonacci R, Ruffié P and Schlumberger M: Neuron-specific enolase and chromogranin A as markers of neuroendocrine tumours. Br J Cancer 78: 1102-1107, 1998.

5. Fan JH, Zhang YQ, Shi SS, Chen YJ, Yuan XH,Jiang LM, Wang SM, Ma L, He YT, Feng CY, et al: A nation-wide retrospective epidemiological study of gastroenteropancreatic neuroendocrine neoplasms in china. Oncotarget 8: 71699-71708, 2017.

6. Yao JC, Hassan M, Phan A, Dagohoy C, Leary C, Mares JE, Abdalla EK, Fleming JB, Vauthey JN, Rashid A and Evans DB: One hundred years after 'carcinoid': Epidemiology of and prognostic factors for neuroendocrine tumors in 35,825 cases in the United States. J Clin Oncol 26: 3063-3072, 2008. 
7. Plöckinger U, Rindi G, Arnold R, Eriksson B, Krenning EP de Herder WW, Goede A, Caplin M, Oberg K, Reubi JC, et al: Guidelines for the diagnosis and treatment of neuroendocrine gastrointestinal tumours. A consensus statement on behalf of the European Neuroendocrine Tumour Society (ENETS). Neuroendocrinology 80: 394-424, 2004.

8. McEntee GP, Nagorney DM, Kvols LK, Moertel CG and Grant CS: Cytoreductive hepatic surgery for neuroendocrine tumors. Surgery 108: 1091-1096, 1990.

9. Bosman FT, Carneiro F, Hruban RH and Theis ND: WHO classification of tumours of the digestive system. 4th Edition. Lyon: International Agency for Research on Cancer, 2010.

10. Chinese Pathologic Consensus Group for Gastrointestinal and Pancreatic Neuroendocrine Neoplasm: China Consensus Guidelines for the standards of histopathologic diagnosis in Gastroenteropancreatic Neuroendocrine neoplasm. Chin J Pathol 40: 257-262, 2011.

11. Modlin IM, Lye KD and Kidd M. A 5-decade analysis of 13,715 carcinoid tumors. Cancer 97: 934-959, 2003.

12. Oberg K, Modlin IM, De Herder W, Pavel M, Klimstra D, Frilling A, Metz DC, Heaney A, Kwekkeboom D, Strosberg J, et al: Consensus on biomarkers for neuroendocrine tumour disease. Lancet Oncol 16: e435-e446, 2015.

13. Yao JC, Pavel M, Phan AT, Kulke MH, Hoosen S, St Peter J, Cherfi A and Öberg KE: Chromogranin A and neuron-specific enolase as prognostic markers in patients with advanced pNET treated with everolimus. J Clin Endocrinol Metab 96: 3741-3749, 2011.

14. Arnold R, Wilke A, Rinke A, Mayer C, Kann PH, Klose KJ, Scherag A, Hahmann M, Müller HH and Barth P: Plasma chromogranin A as marker for survival in patients with metastatic endocrine gastroenteropancreatic tumors. Clin Gastroenterol Hepatol 6: 820-827, 2008.

15. Jianming X, Houjie L, Shukui Q and Hui LW: Expert consensus on neuroendocrine tumors of the pancreas and stomach in China. J Clini Oncol 21: 927-946, 2016.

16. Jun E, Kim SC, Song KB, Hwang DW, Lee JH, Shin SH, Hong SM, Park KM and Lee YJ: Diagnostic value of chromogranin A in pancreatic neuroendocrine tumors depends on tumor size: A prospective observational study from a single institute. Surgery 162: 120-130, 2017.

17. Cimitan M, Buonadonna A, Cannizzaro R, Canzonieri V, Borsatti E, Ruffo R and De Apollonia L: Somatostatin receptor scintigraphy versus chromogranin A assay in the management of patients with neuroendocrine tumors of different types: Clinical role. Ann Oncol 14: 1135-1141, 2003.
18. Basturk O, Yang Z, Tang LH, Hruban RH, Adsay V, McCall CM, Krasinskas AM, Jang KT, Frankel WL, Balci S, et al: The high-grade (WHO G3) pancreatic neuroendocrine tumor category is morphologically and biologically heterogenous and includes both well differentiated and poorly differentiated neoplasms. Am J Surg Pathol 39: 683-690, 2015.

19. Hijioka M, Ito T, Igarashi H, Fujimori N, Lee L, Nakamura T, Jensen RT and Takayanagi R: Serum chromogranin A is a useful marker for Japanese patients with pancreatic neuroendocrine tumors. Cancer Sci 105: 1464-1471, 2014.

20. Qiao XW, Qiu L, Chen YJ, Meng CT, Sun Z, Bai CM, Zhao DC, Zhang TP, Zhao YP, Song YL, et al: Chromogranin A is a reliable serum diagnostic biomarker for pancreatic neuroendocrine tumors but not for insulinomas. BMC Endocr Disord 14: 64 , 2014.

21. Wang YH, Yang QC, Lin Y, Xue L, Chen MH and Chen J: Chromogranin A as a marker for diagnosis, treatment, and survival in patients with gastroenteropancreatic neuroendocrine neoplasm. Medicine (Baltimore) 93: e247, 2014.

22. Kloppel G, Couvelard A, Perren A, Komminoth P, McNicol AM, Nilsson O, Scarpa A, Scoazec JY, Wiedenmann B, Papotti M, et al: ENETS Consensus guidelines for the standards of care in neuroendocrine tumors: Towards a standardized approach to the diagnosis of gastroenteropancreatic neuroendocrine tumors and their prognostic stratification. Neuroendocrinology 90: 162-166, 2009.

23. Lai M, Lü B, Xing X, Xu E, Ren G and Huang Q: Secretagogin, a novel neuroendocrine marker, has a distinct expression pattern from chromogranin A. Virchows Arch 449: 402-409, 2006.

24. Xing X, Lai M, Gartner W, Xu E, Huang Q, Li H and Chen G: Identification of differentially expressed proteins in colorectal cancer by proteomics: Down-regulation of secretagogin. Proteomics 6: 2916-2923, 2006.

25. D'Alessandro M, Mariani P, Lomanto D, Carlei F, Lezoche E and Speranza V: Serum neuron-specific enolase in diagnosis and follow-up of gastrointestinal neuroendocrine tumors. Tumour Biol 13: 352-357, 1992.

26. Cunningham RT, Johnston CF, Irvine GB and Buchanan KD: Serum neurone-specific enolase levels in patients with neuroendocrine and carcinoid tumours. Clin Chim Acta 212: 123-131, 1992.

27. Oishi $\mathrm{S}$ and Sato T: Elevated serum neuron-specific enolase in patients with malignant pheochromocytoma. Cancer 61: 1167-1170, 1988 